\title{
sciendo
}

Current Issues in Pharmacy and Medical Sciences

Formerly ANNALES UNIVERSITATIS MARIAE CURIE-SKLODOWSKA, SECTIO DDD, PHARMACIA

journal homepage: http://www.curipms.umlub.pl/

\section{Comparative efficacy of empagliflozin versus placebo in the treatment of type 1 diabetes mellitus: a meta-analysis of randomized controlled trials}

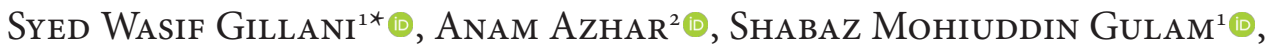 \\ Fithawit Bahran Gebreigziabher ${ }^{1} \oplus$, Hassaan Anwer Rathore ${ }^{3} \odot$
}

\footnotetext{
${ }^{1}$ Department of Pharmacy Practice, College of Pharmacy Gulf Medical University, Ajman, United Arab Emirates

2 Pharm D candidates, College of Pharmacy Gulf Medical University, Ajman, United Arab Emirates

${ }^{3}$ College of Pharmacy, Qatar University, Doha, Qatar
}

\begin{tabular}{|c|c|}
\hline ARTICLE INFO & ABSTRACT \\
\hline $\begin{array}{l}\text { Received } 06 \text { January } 2021 \\
\text { Accepted } 12 \text { June } 2021\end{array}$ & $\begin{array}{l}\text { The objective of this meta-analysis study was to evaluate the comparative efficacy of } \\
\text { empagliflozin }(25 \mathrm{mg}) \text { with placebo in the treatment and management of type } 1 \text { diabetes }\end{array}$ \\
\hline $\begin{array}{l}\text { Keywords: } \\
\text { meta-analysis, } \\
\text { type } 1 \text { diabetes, } \\
\text { empagliflozin, } \\
\text { placebo, } \\
\text { evidence-based practice. }\end{array}$ & $\begin{array}{l}\text { mellitus. This study is a meta-analysis, so an ethical statement is not required. Different } \\
\text { databases and individual journal websites like SCOPUS, Science direct, Cochrane review } \\
\text { library etc. were used. The articles were evaluated based on the search and eligibility } \\
\text { criteria. A total of five RCTs were incorporated in this meta-analysis. These studies } \\
\text { contained a total of } 1058 \text { patients, including } 526 \text { patients with placebo (or control-treated } \\
\text { patients), and } 532 \text { patients with empagliflozin }(25 \mathrm{mg} \text { ) treated combination. The mean } \\
\text { follow-up time ranged from } 7 \text { days to } 6 \text { months. Overall, mean reduction in placebo was } \\
-0.50 \% \text { and empa-treated was }-0.85 \% \text {, while the pooled WMD was } 3.82995 \% \text { CI } 1.20- \\
5.88, p=0.0001) \text {. Regarding urinary glucose excretion, that the pooled WMD was } 6.67 \\
(95 \% \text { CI } 4.87-10.14, p=0.001) \text { indicated a significant increase in empa-arm compared } \\
\text { to placebo. No heterogeneity was found (I } 2-15.03 \%) \text {. This meta-analysis underlined } \\
\text { the therapeutic benefit of empagliflozin as an adjunctive therapy for patients with type } 1 \\
\text { diabetes. }\end{array}$ \\
\hline
\end{tabular}

\section{INTRODUCTION}

Diabetes Mellitus is an endocrine disorder that is the leading cause of morbidity and mortality owing to complications like nephropathy, retinopathy and cardiovascular disorders [1]. Type $1 \mathrm{DM}$ affects about 1.5 million people in the US alone. Over $10 \%$ of all patients who were at first diagnosed with type 2 diabetes, later on show evidence that T2D progresses to T1D. This is one of the reasons why the prevalence of T1D is currently increasing rapidly and why insulin dependence has escalated, because as of now, insulin administration is the only efficacious treatment available for T1D [2-3]. Chronic exposure to hyperglycemia in type 1 diabetes carries an increased risk of micro and macro vascular diseases [4].

Regardless of the accessibility of insulin analogs, insulin pumps and CGM systems, the T1D Exchange (T1DX) registry - which includes a group of individuals with T1D

\footnotetext{
* Corresponding author

e-mail: dr.syedwasif@gmu.ac.ae
}

that participate in research receiving care in some of the major centers in the US, shows that only $20 \%$ of all adult patients attain the $\mathrm{HbA} 1 \mathrm{C}$ target of $7 \%(53 \mathrm{mmol} / \mathrm{mol})$ as recommended by the American Diabetes Association $[1,3]$. It is understood that patients who are not a part of these centers may have an even worse glycemic control [4-5].

Insulin therapy that is currently being used has several drawbacks. These include inceased glucose variability, weight gain and severe hypoglycemia [1-3,5]. This is because the insulin system being applied to date lacks feedback inhibition, has only peripheral drug delivery, and decreases response to hypoglycemia. Due to these reasons, controlling glycemic variability in T1D individuals is quite challenging and hence requires adjunct pharmacotherapies to complement insulin replacement $[1,6]$.

Sodium-glucose transporter 2 (SGLT2) inhibitors are a class of drugs that block the SGLT2 transporter in the proximal renal tubule that leads to glycosuria and natriuretic that are currently approved and used for type 2 diabetes. 
The administration of dual SGLT1 with 2 inhibitors also has the advantage of delayed intestinal absorption of glucose and galactose, as SGLT1 receptors are present in the gastrointestinal tract [4-7].

These drugs are proven to have cardiovascular and renal protective effects in T2DM as they lower the risk of hypoglycemia and are orally administered. Thus, they are now being studied for their application in T1D [8-9]. Several clinical trials of SGLT2 inhibitors added to intensified insulin therapy in adults with type 1 diabetes have shown moderate reductions in $\mathrm{HbA} 1 \mathrm{C}$, glycemic variability, total daily insulin dose, blood pressure, and body weight and increased time in range without an increase in hypoglycemia, and are accompanied by significant patient-reported benefits [1-2]. Ipragliflozin is an SGLT2 inhibitor that is available in Japan, Korea and Thailand [10]. It is approved in Japan for adjunct therapy with insulin for T1D, as is sotagliflozin, which is a dual SGLT1+2 inhibitor that is also used in combination with insulin. The administration of this has demonstrated improvements in $\mathrm{HbA} 1 \mathrm{C}$, weight loss, systolic blood pressure and also allowed a reduction in total insulin dose [7-9].

Therefore, the objective of this meta-analysis study was to evaluate the comparative efficacy of empagliflozin (25 mg) with placebo in the treatment and management of Type 1 diabetes mellitus (T1DM) patients by extracting data and evidence synthesis from randomized controlled trials.

\section{METHODOLOGY}

This study is a meta-analysis, hence an ethical statement is not required.

\section{Data sources and searches}

A detailed search was undertaken for randomized clinical trials in clinical databases subject-focused on the key terms 'SGLT2 inhibitors', 'empagliflozin' of dose $25 \mathrm{mg}$.

\section{Primary search}

The meta-analysis used for primary search encompassed different databases and individual journal websites like SCOPUS, Science direct, Cochrane review library, American diabetes association (Diabetes care), Wiley online library, Endocrine Web, Touch endocrinology, The San Diego Union-Tribune, PubMed (NCBI), PROSPERO, TRIP, as well as Medline and Clinical trial registry.

\section{Study Selection}

The articles were evaluated based on the search and eligibility criteria, and included in the meta-analysis, articles that were accepted between 2014-2020 that focused on:

a) empagliflozin as an adjunct therapy;

b) reduction of $\mathrm{HbA} 1 \mathrm{C}$;

c) randomized clinical trials done on Type 1 diabetic patients;

d) diabetic ketoacidosis which occurred due to prolonged use of SGLT2;

e) safety and efficacy of SGLT2i;

f) improvements in weight loss and systolic blood pressure; g) reduction in daily insulin dose;

h) inhibition of intestinal glucose absorption with SGLT2i.

No articles before these years were taken into consideration. Articles specifically about Type 2 diabetes were excluded. Primary literature would be specific only for safety and efficacy of SGLT2i in Type 1 diabetes.

\section{Bias Risk Measure and Data extraction}

The titles and abstracts were reviewed according to the inclusion and exclusion criteria and PICO. In the second step of screening, duplicates, as well as inappropriate studies and studies which were not in the eligibility criteria mentioned above, were removed. The articles were assessed based on the literature, publication year, study design, patient population and type of diabetes considered; for example, literature that focused on gestational diabetes or type 2 diabetes were excluded.

Two primary authors of this study served as independent reviewers to assess the quality and bias risk assessment of each study by using Cochrane instrument $[11,12]$. The criteria for evaluations included random sequence generation, as well as double-blinding that embraced blinding of the investigators and the participants, detection bias and assessment of incomplete outcome data and baseline clinical characteristics. Studies with 3 or more bias risks were considered ineligible for data synthesis and analysis. A standardized data extraction form was used to evaluate the quality of identified studies. Any form of disagreement on findings between reviewers was resolved by discussion.

Data retrieved from studies included the first author's name, year, country of origin, number of patients, therapy period, intervention method, baseline data and post-intervention outcomes. Some data was not available online; herein, good faith efforts were applied to obtain the data via emails to the corresponding author or by researching for associated conference proceedings and by mining other articles citing the study in question.

\section{Data Synthesis, Primary and Secondary variables}

Pooled analysis was performed to determine the efficacy of SGLT2 inhibitors versus placebo on the duration for reduction of $\mathrm{HbA} 1 \mathrm{C}$, effect on fasting blood sugar, postprandial plasma glucose, body weight, urinary glucose excretion, total daily insulin dose, estimated glomerular filtration rate and mean daily glucose.

\section{Data Analysis}

STATA software 8.0 was used to perform statistical analysis. The weighted mean difference and the $95 \%$ confidence interval were calculated for each outcome. Standard deviation and sample size were taken into consideration to calculate the weight given to each study. The standard deviations not mentioned were obtained from the Cochrane Handbook or were calculated. Forest plots were used for reporting of adverse events. Heterogeneity was evaluated using $\mathrm{I}^{2}$ statistics, and a $p$ value of less than 0.05 was considered statistically significant. Dichotomous data were chosen for adverse events reporting or hypoglycemic events. The odds ratio (OR) and 95\% CI was used as the effect parameter 
in clinical parameters. The Egger test and inverted funnel plots were applied to evaluate publication bias.

\section{RESULTS}

\section{Literature Search}

A total of 1,540 articles were identified using the search strategies, out of which 1165 were rejected based on review of titles and abstracts. Consequently, 420 full-text articles were evaluated for eligibility, from which 415 articles were excluded since they did not meet the inclusion criteria. All the eligible articles were reviewed for quality assessment. Finally, a total of five RCTs [13-17] were included in this meta-analysis. Detailed procedure is provided in PRIMSA diagram (Figure 1). These studies contained a total of 1058 patients, including 526 patients with placebo or controltreated patients, and 532 patients with empagliflozin $(25 \mathrm{mg})$ - treated combination. The reference lists of these articles were also searched for overlook studies. All the assessment and procedural steps were independently performed by two-reviewers.

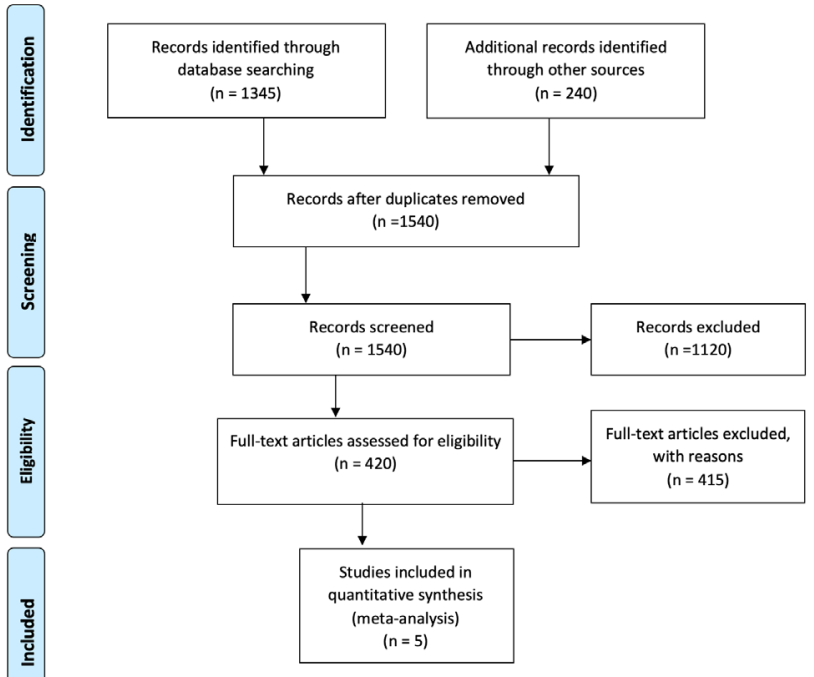

Figure 1. PRISMA reporting diagram of RCT

\section{Quality assessment}

The quality of each study was measured using Cochrane instrument, and the same was used to evaluate the risk of bias as well. All five studies included for data synthesis and analysis did not reveal any known bias (Table 1).

Table 1. Quality assessment of RCTs as per Cochrane tool

\begin{tabular}{|l|c|c|c|c|c|}
\hline & $\begin{array}{c}\text { EASE 1 } \\
2017\end{array}$ & $\begin{array}{c}\text { EASE 2 } \\
2018\end{array}$ & $\begin{array}{c}\text { EASE 3 } \\
2018\end{array}$ & $\begin{array}{c}\text { Akira et al. } \\
2018\end{array}$ & $\begin{array}{c}\text { Pieber et al. } \\
2015\end{array}$ \\
\hline $\begin{array}{l}\text { Random } \\
\text { sequence } \\
\text { generation }\end{array}$ & + & + & + & + & + \\
\hline $\begin{array}{l}\text { Allocation } \\
\text { concealment }\end{array}$ & + & + & + & + & + \\
\hline $\begin{array}{l}\text { Blinding } \\
\text { of participants }\end{array}$ & + & + & + & + & + \\
\hline $\begin{array}{l}\text { Blinding } \\
\text { of outcome } \\
\text { assessments }\end{array}$ & - & + & + & - & + \\
\hline $\begin{array}{l}\text { Incomplete } \\
\text { outcome data }\end{array}$ & - & - & - & - & - \\
\hline
\end{tabular}

\section{Main Characteristic}

Overall, 5 RCTs [13-17] were included in this metaanalysis. The mean follow-up time ranged from 7 days to 6 months. All the included patients had type 1 diabetes mellitus (T1DM). The dose of empagliflozin was $25 \mathrm{mg}$ daily. The combination of insulin plus empagliflozin was used to treat T1DM in all 5 RCTs versus insulin plus placebo.

\section{Mean Hb1Ac Reduction}

The data on mean Hb1 Ac (\%) were available in all 5 RCTs (Table 2a). Overall, mean reduction in placebo was $-0.50 \%$ and empa-treated was $-0.85 \%$. The pooled WMD was 3.82 (95\% CI $1.20-5.88, \mathrm{p}=0.0001)$, indicating three times more reduction in glycated hemoglobin (\%) value in empa-treated (Table 2b). No significant heterogeneity was found $\left(\mathrm{I}^{2}-5.2 \%\right)$. The inverted funnel plots of these RCTs appeared symmetrical.

Table 2a. Comparison of Mean Hb1Ac reduction

\begin{tabular}{|l|c|c|c|c|c|}
\hline $\begin{array}{l}\text { Hb1Ac Mean } \\
\text { Reduction }\end{array}$ & Placebo & $\begin{array}{c}\text { Empa } \\
(25 \mathrm{mg})\end{array}$ & WMD & $95 \%$ CI & p-value \\
\hline $\begin{array}{l}\text { EASE 1 } \\
2017\end{array}$ & -0.47 & -0.60 & 2.96 & $1.20-4.12$ & 0.001 \\
\hline $\begin{array}{l}\text { EASE } 2 \\
2018\end{array}$ & -0.52 & -0.65 & 3.25 & $1.78-4.87$ & 0.001 \\
\hline $\begin{array}{l}\text { EASE } 3 \\
2018\end{array}$ & -0.54 & -0.67 & 3.37 & $1.46-4.56$ & 0.002 \\
\hline $\begin{array}{l}\text { Akira at al., } \\
2018\end{array}$ & -0.47 & -0.91 & 5.21 & $2.41-5.96$ & 0.001 \\
\hline $\begin{array}{l}\text { Pieber et al., } \\
2015\end{array}$ & -0.50 & -0.61 & 3.02 & $1.42-3.78$ & 0.001 \\
\hline
\end{tabular}

Weighted mean difference; $\mathrm{p}$-value $(0.05)$ considered significant

Table $2 \boldsymbol{b}$. Comparison of mean Hb1Ac. (Heterogeneity $\mathrm{I}^{2}-5.2 \%$ ).

\begin{tabular}{|c|c|c|c|c|c|}
\hline $\begin{array}{l}\text { Hb1Ac Mean } \\
\text { Reduction }\end{array}$ & Placebo & $\begin{array}{c}\text { Empa } \\
(25 \mathrm{mg})\end{array}$ & $\begin{array}{l}\text { Overall } \\
\text { WMD }\end{array}$ & $95 \%$ CI & $\mathrm{p}$-value \\
\hline $\begin{array}{l}\text { EASE } 1 \\
2017\end{array}$ & -0.47 & -0.60 & \multirow{5}{*}{3.82} & \multirow{5}{*}{$1.20-5.88$} & \multirow{5}{*}{0.001} \\
\hline $\begin{array}{l}\text { EASE } 2 \\
2018\end{array}$ & -0.52 & -0.65 & & & \\
\hline $\begin{array}{l}\text { EASE } 3 \\
2018\end{array}$ & -0.54 & -0.67 & & & \\
\hline $\begin{array}{l}\text { Akira et al., } \\
2018\end{array}$ & -0.47 & -0.91 & & & \\
\hline $\begin{array}{l}\text { Pieber et al., } \\
2015\end{array}$ & -0.50 & -0.61 & & & \\
\hline
\end{tabular}

Weighted mean difference; $\mathrm{p}$-value (0.05) considered significant

\section{Urinary Glucose excretion}

The data of this variable was available in all 5 RCTs (Table 3). Overall increase of urinary glucose excretion was found in both arms. The pooled WMD was 6.67 (95\% CI $4.87-10.14, \mathrm{p}=0.001)$ indicating a significant increase in urinary glucose excretion in empa-arm compared to placebo. No heterogeneity was found $\left(\mathrm{I}^{2}-15.03 \%\right)$.

Table 3. Comparison of mean urinary glucose excretion increase (Heterogeneity I $\mathrm{I}^{2}-15.03 \%$ )

\begin{tabular}{|c|c|c|c|c|c|}
\hline \begin{tabular}{|c|}
$\begin{array}{c}\text { Urinary Glucose } \\
\text { Excretion }\end{array}$ \\
\end{tabular} & Placebo & $\begin{array}{c}\text { Empa } \\
(25 \mathrm{mg})\end{array}$ & $\begin{array}{l}\text { Overall } \\
\text { WMD }\end{array}$ & $95 \% \mathrm{CI}$ & $\mathrm{p}$-value \\
\hline \begin{tabular}{|l|} 
EASE 1 \\
2017 \\
\end{tabular} & 4.9 & 99.1 & \multirow{5}{*}{6.67} & \multirow{5}{*}{$4.87-10.14$} & \multirow{5}{*}{0.001} \\
\hline $\begin{array}{l}\text { EASE } 2 \\
2018\end{array}$ & 5.2 & 100.4 & & & \\
\hline \begin{tabular}{|l|} 
EASE 3 \\
2018 \\
\end{tabular} & 3.7 & 101.2 & & & \\
\hline $\begin{array}{l}\text { Akira et al., } \\
2018\end{array}$ & 4.3 & 97.6 & & & \\
\hline $\begin{array}{l}\text { Pieber et al., } \\
2015\end{array}$ & 1.61 & 108.4 & & & \\
\hline
\end{tabular}

Weighted mean difference; $\mathrm{p}$-value (0.05) considered significant 


\section{Daily Insulin dose-reduction}

The data of this variable was available in all 5 RCTs (Table 4). Overall no signification change was found in RCTs for both arms. The pooled WMD was 1.02 (95\% CI 0.41-1.20, $\mathrm{p}=0.152$ ) indicating no effect of empa-combination on the reduction of insulin daily dosing compared to placebo. No reported heterogeneity was indicated $\left(\mathrm{I}^{2}-27.1 \%\right)$. The Egger test results showed no influence of publication bias on this outcome.

Table 4. Comparison of Mean daily insulin dose reduction (Heterogeneity I ${ }^{2}-27.1 \%$ )

\begin{tabular}{|c|c|c|c|c|c|}
\hline $\begin{array}{l}\text { Daily Insulin } \\
\text { dose Mean } \\
\text { Reduction }\end{array}$ & Placebo & $\begin{array}{c}\text { Empa } \\
(25 \mathrm{mg})\end{array}$ & $\begin{array}{l}\text { Overall } \\
\text { WMD }\end{array}$ & $95 \% \mathrm{CI}$ & $\mathrm{p}$-value \\
\hline $\begin{array}{l}\text { EASE } 1 \\
2017 \\
\end{array}$ & -0.23 & -0.23 & \multirow{5}{*}{1.02} & \multirow{5}{*}{$0.41-1.20$} & \multirow{5}{*}{0.152} \\
\hline $\begin{array}{l}\text { EASE } 2 \\
2018\end{array}$ & -0.23 & -0.26 & & & \\
\hline $\begin{array}{l}\text { EASE } 3 \\
2018 \\
\end{array}$ & -0.21 & -0.24 & & & \\
\hline $\begin{array}{l}\text { Akira at al. } \\
2018\end{array}$ & -0.22 & -0.15 & & & \\
\hline $\begin{array}{l}\text { Pieber et al. } \\
2015\end{array}$ & -0.23 & -0.22 & & & \\
\hline
\end{tabular}

\section{Estimated Glomerular Filtration Rate (eGFR)}

The data was retrieved from all the five RCTs (Table 5). Overall, the findings were inconclusive and asymmetrical data was found with inverted funnel plot. The pooled WMD was 1.87 (95\% CI 1.02-2.43, p=0.001) and indicated decrease in eGFR over time in the empa-treated arm, as compared to placebo. Heterogeneity was found to exist $\left(\mathrm{I}^{2}-27.1 \%, \mathrm{p}=0.01\right)$. The Egger test showed no influence of publication bias on this outcome.

Table 5. Comparison of Mean estimated Glomerular Filtration Rate (eGFR) (Heterogeneity I ${ }^{2}-52.4 \%$ )

\begin{tabular}{|l|c|c|c|c|c|}
\hline \multicolumn{1}{|c|}{ eGFR } & Placebo & $\begin{array}{c}\text { Empa } \\
(25 \mathrm{mg})\end{array}$ & $\begin{array}{c}\text { Overall } \\
\text { WMD }\end{array}$ & 95\% CI & p-value \\
\cline { 1 - 3 } $\begin{array}{l}\text { EASE } 1 \\
2017\end{array}$ & 0.30 & -0.81 & & & \\
\cline { 1 - 3 } $\begin{array}{l}\text { EASE } 2 \\
2018\end{array}$ & 0.21 & -0.56 & \multirow{2}{*}{1.87} & $1.02-2.43$ & 0.001 \\
\cline { 1 - 3 } $\begin{array}{l}\text { EASE } 3 \\
2018\end{array}$ & -0.10 & -0.45 & & \\
\cline { 1 - 3 } $\begin{array}{l}\text { Akira at al. } \\
2018\end{array}$ & 0.43 & -0.56 & & & \\
\cline { 1 - 3 } $\begin{array}{l}\text { Pieber et al. } \\
2015\end{array}$ & -0.18 & -0.87 & & & \\
\hline
\end{tabular}

Weighted mean difference; $\mathrm{p}$-value $(0.05)$ considered significant

\section{Fasting Plasma Glucose and Mean Daily Glucose}

The data for this outcome was extracted from all 5 RCTs (Table 6a, b). Overall, analysis showed significant reduction of both FPG and MDG in the empa-treated arm, as compared to placebo. The pooled WMD in FPG 4.72 (95\% CI 2.16$8.51, \mathrm{p}=0.001)$ and MDG $2.46(95 \%$ CI 1.02-3.87, $\mathrm{p}=0.001)$ indicated significant reduction of these outcome variables in the empa-treated arm, as compared with placebo. No heterogeneity was reported with FPG at $\mathrm{I}^{2}-10.01 \%$ and MDG at $\mathrm{I}^{2}-5.6 \%$.

\section{Effect on body weight}

The data for this outcome was extracted from all 5 RCTs (Table 6c). Overall, analysis showed significant reduction of bodyweight in the empa-treat arm, as compared to placebo. The pooled WMD was 3.81 (95\% CI 2.92-6.33, $\mathrm{p}=0.001)$, indicating significant reduction in variables within the empatreated arm, as compared with placebo. No heterogeneity was reported $\left(\mathrm{I}^{2}-0 \%\right)$.

Table 6a. Comparison of Fasting Plasma Glucose (FPG) value (Heterogeneity $\mathrm{I}^{2}-10.01 \%$ )

\begin{tabular}{|c|c|c|c|c|c|}
\hline FPG & Placebo & $\begin{array}{c}\text { Empa } \\
(25 \mathrm{mg})\end{array}$ & $\begin{array}{l}\text { Overall } \\
\text { WMD }\end{array}$ & $95 \%$ CI & $\mathrm{p}$-value \\
\hline $\begin{array}{l}\text { EASE } 1 \\
2017\end{array}$ & -0.02 & -1.81 & \multirow{5}{*}{4.72} & \multirow{5}{*}{$2.16-8.51$} & \multirow{5}{*}{0.001} \\
\hline $\begin{array}{l}\text { EASE } 2 \\
2018\end{array}$ & -0.11 & -0.94 & & & \\
\hline $\begin{array}{l}\text { EASE } 3 \\
2018 \\
\end{array}$ & -0.07 & -1.45 & & & \\
\hline $\begin{array}{l}\text { Akira at al., } \\
2018\end{array}$ & -0.04 & -4.23 & & & \\
\hline $\begin{array}{l}\text { Pieber et al., } \\
2015\end{array}$ & -0.18 & -1.96 & & & \\
\hline
\end{tabular}

Table 6b. Comparison of Mean Daily Glucose (MDG) value (Heterogeneity $\mathrm{I}^{2}-5.6 \%$ )

\begin{tabular}{|l|c|c|c|c|c|}
\hline \multicolumn{1}{|c|}{ FPG } & Placebo & $\begin{array}{c}\text { Empa } \\
(25 \mathrm{mg})\end{array}$ & $\begin{array}{c}\text { Overall } \\
\text { WMD }\end{array}$ & 95\% CI & p-value \\
\hline \begin{tabular}{l|c|c|c|} 
EASE 1 \\
2017
\end{tabular} & -0.02 & -0.94 & & & \\
\cline { 1 - 3 } $\begin{array}{l}\text { EASE } 2 \\
2018\end{array}$ & -0.07 & -0.76 & & & \\
\cline { 1 - 3 } $\begin{array}{l}\text { EASE } 3 \\
2018\end{array}$ & -0.04 & -1.06 & 2.46 & $1.02-3.87$ & 0.001 \\
\cline { 1 - 3 } $\begin{array}{l}\text { Akira at al. } \\
2018\end{array}$ & -0.03 & -0.87 & & & \\
\cline { 1 - 3 } $\begin{array}{l}\text { Pieber et al. } \\
2015\end{array}$ & -0.14 & -0.61 & & & \\
\hline
\end{tabular}

Table 6 c. Comparison of Mean bodyweight change (Heterogeneity $\left.\mathrm{I}^{2}-0 \%\right)$

\begin{tabular}{|c|c|c|c|c|c|}
\hline Bodyweight & Placebo & $\begin{array}{c}\text { Empa } \\
(25 \mathrm{mg})\end{array}$ & $\begin{array}{l}\text { Overall } \\
\text { WMD }\end{array}$ & $95 \%$ CI & $\mathrm{p}$-value \\
\hline $\begin{array}{l}\text { EASE } 1 \\
2017\end{array}$ & -0.08 & -3.1 & \multirow{5}{*}{3.81} & \multirow{5}{*}{$2.92-6.33$} & \multirow{5}{*}{0.001} \\
\hline $\begin{array}{l}\text { EASE } 2 \\
2018 \\
\end{array}$ & -0.01 & -3.3 & & & \\
\hline $\begin{array}{l}\text { EASE } 3 \\
2018 \\
\end{array}$ & -0.03 & -3.4 & & & \\
\hline $\begin{array}{l}\text { Akira at al. } \\
2018\end{array}$ & -0.06 & -1.8 & & & \\
\hline $\begin{array}{l}\text { Pieber et al. } \\
2015\end{array}$ & -0.01 & -2.8 & & & \\
\hline
\end{tabular}

Weighted mean difference, $\mathrm{p}$-value (0.05) considered significant

\section{Hypoglycemia reported events}

The data for this outcome was extracted from all 5 RCTs (Figure 2). Overall, analysis showed high incidences of hypoglycemic reported events in the placebo arm, as compared with the empa-treated arm. The pooled OD was 0.81 (95\% CI 0.49-1.09, $\mathrm{p}=0.001)$, indicating $19 \%$ reduction in hypoglycemic event rates in the empa-treated arm, as compared with placebo. No heterogeneity was found $\left(\mathrm{I}^{2}-31.1 \%\right)$. The inverted funnel plots of these RCTs appeared symmetrical. The Egger test showed no influence of publication bias on this outcome.

\section{All patient reported adverse events}

The data for this outcome was extracted from all 5 RCTs (Figure 3). Overall, analysis showed high incidences of hypoglycemic reported events in the placebo arm, as compared with the empa-treated arm. The pooled OD was 0.72 (95\% CI $0.45-0.98, \mathrm{p}=0.0001)$, indicating $28 \%$ reduction in all patient reported adverse events in the empa-treated arm, as compared with placebo. No heterogeneity was found $\left(\mathrm{I}^{2}-0 \%\right)$. The inverted funnel plots of these RCTs appeared symmetrical. 


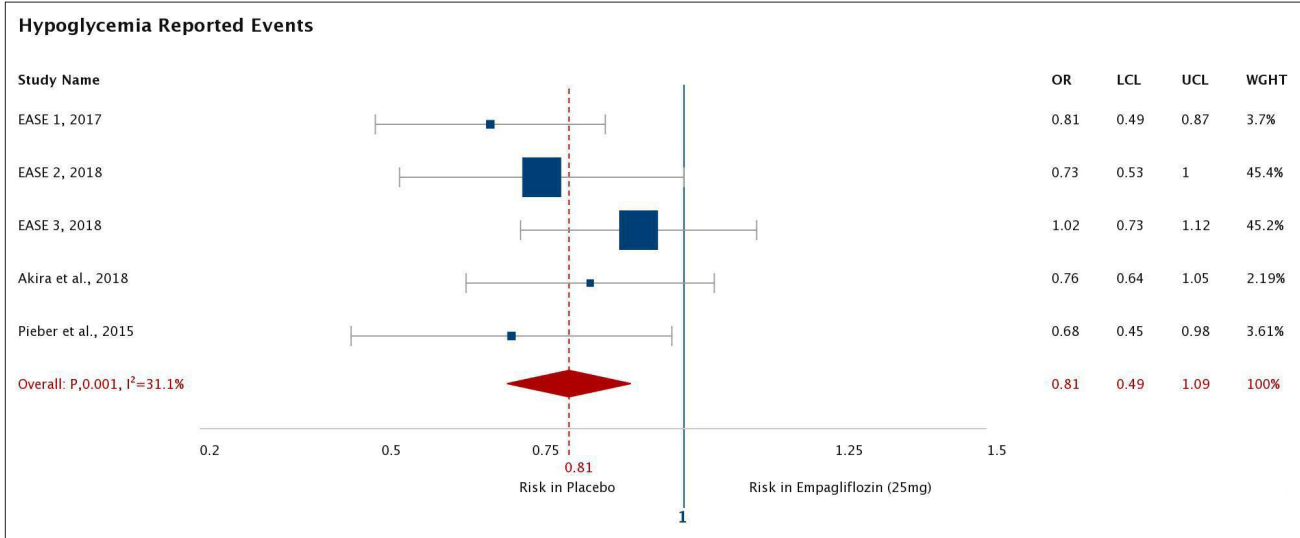

Figure 2. Hypoglycemic reported events

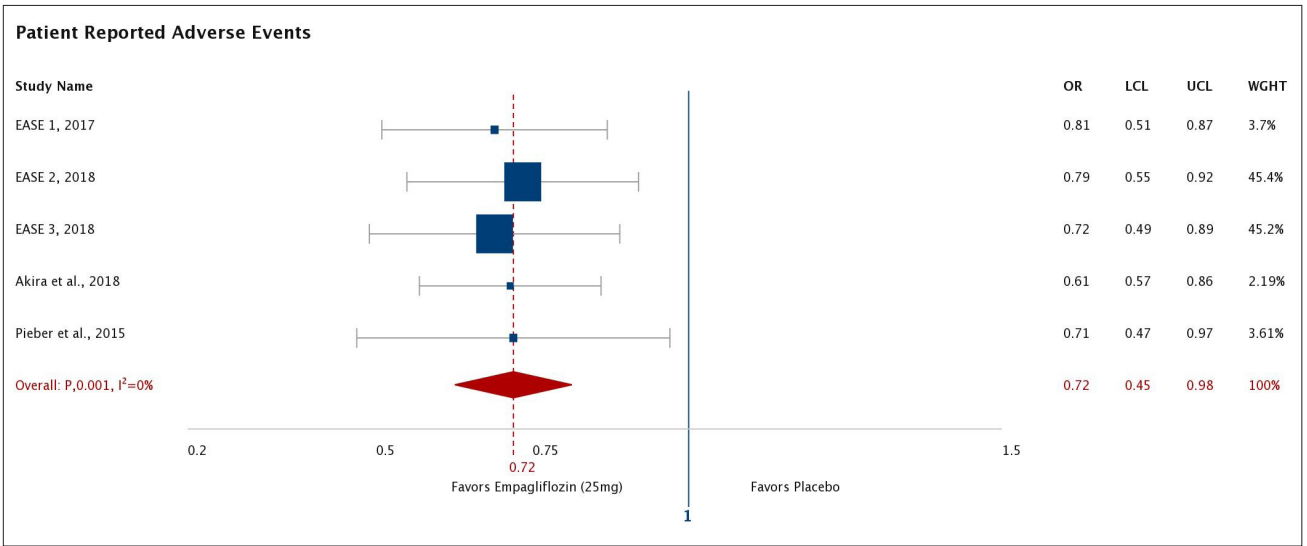

Figure 3. Patient reported adverse events

\section{DISCUSSION}

Investigating the use of empagliflozin in type 1 diabetic participants, The EASE (Empagliflozin as Adjunctive to insulin therapy) double blind, place controlled phase 3 studies were one of the initial reports that analyzed efficacy with various dosing methods of empagliflozin and their safety profiles. The program reported a mean glycated haemoglobin reduction of $-0.54 \%(-0.65,-0.42)$ and $-0.53 \%$ $(-0.65,-0.42)$ for empagliflozin $10 \mathrm{mg}$ and $25 \mathrm{mg}$ doses, respectively, in addition to observed benefits such as reduction in weight of participants, as well as decreased blood pressure readings. These outcomes demonstrate the benefits of empagliflozin administration in type 1 diabetes. The maximal reduction in glycated haemoglobin was observed from week 12 and seen as dose dependent from week 26 onwards. A statistically significant $(p<0.0001)$ reduction in fasting plasma glucose was also observed (up to $-35.2 \mathrm{mg}$ / $\mathrm{dL}$ at week 26 of treatment) [13]. Similar results were noted in a smaller scale 4 week randomized, double blind and placebo controlled phase 2 trial, with mean glycated haemoglobin reduction of $-0.20 \%,-0.35 \%$ and $-0.20 \%$, with empagliflozin doses of $2.5 \mathrm{mg}, 10 \mathrm{mg}$ and $25 \mathrm{mg}$, respectively. The study reported significant mean reductions in fasting plasma glucose of $-14.27 \mathrm{mg} / \mathrm{dL}$ with $2.5 \mathrm{mg} ;-43.63 \mathrm{mg} / \mathrm{dL}$ with $10 \mathrm{mg}$; $-59.57 \mathrm{mg} / \mathrm{dL}$ with $25 \mathrm{mg}$, in addition to reductions in body weight and blood pressure [15]. The efficacy of empagliflozin in reducing plasma glucose levels and supporting glycemic control in Type 1 diabetic participants is also reflected in other studies $[16,17]$. Reduction in fasting plasma glucose levels however, may contribute to reduction in adjusted insulin dosing and minimizing detection of ketoacidosis based on plasma glucose monitoring, thus precipitating the risk of DKA in Type 1 diabetic participants $[18,19]$.

The reduction in plasma glucose and HbA1C levels with empagliflozin was supported with the increased urinary glucose excretion (Table 3). This increase in urinary glucose excretion is a further advantage in Type 1 diabetic participants, as it results in maintenance of lifestyle interventions through caloric loss and reduction in weight and waist circumference $[16,18]$. However, certain considerations need to be applied, as the reduction in plasma glucose levels due to increased urinary excretion can minimize detection of ketosis based on plasma glucose monitoring. Awareness of the symptoms of ketosis, as well as the monitoring of ketones should be applied to aid early detection of DKA [19]. Association of reported higher incidences of genital infection and volume depletion in those receiving empagliflozin, compared to placebo, is another factor that may influence patient's preference in receiving the adjunct therapy [13].

The adjustment of total daily insulin dose varied across the trials investigating the use of SGLT2i as an adjunct therapy in type 1 diabetes. Studies have reported minor non-significant reductions in total daily insulin dose in participants receiving empagliflozin therapy, as compared with placebo (Table 4). The effect upon the participants was the main drive for these reductions, as adjustments were carried out based on plasma glucose monitoring in order to avoid hypoglycemia. These studies also reported increased carbohydrate intake among participants receiving empagliflozin $[13,15]$. Indeed, an open label proof of concept trial reported a significant increase in carbohydrate intake among the type 1 diabetic participants receiving empagliflozin adjunct therapy (from $177 \mathrm{~g} / 24 \mathrm{~h}$, to $229 \mathrm{~g} / 24 \mathrm{~h}$ ). This is potentially a result of increased urinary glucose excretion. The outcome of this is a reduced need to lower prandial insulin dose in order to compensate for the increased carbohydrate intake. To minimize the risk of hypoglycemia, reduction in total daily dose of insulin was favored more towards basal insulin 
dose compared to prandial dose [16]. However, reduction of basal insulin dose may play a role in reduced suppression of lipolysis and ketogenesis, precipitating DKA even during controlled plasma glucose readings. When reduction in insulin dosing is required in well-controlled plasma glucose levels, subsequent reduction in carbohydrate intake is recommended to avoid a rise in ketogenesis. Adding empagliflozin to the insulin regimen in type 1 diabetic participants may not necessarily impact total daily insulin requirement, and this concept is favorable - as a reduction in insulin doses when added to other predisposing factors, can exacerbate the risk of DKA unless monitored closely $[19,20]$.

The main concern with the use of SGLT2 inhibitors in type 1 diabetic patients is the potentially increased risk of Diabetic Ketoacidosis precipitating to the risk already present in type 1 diabetes [14]. The EASE program reported a higher rated of diabetic ketoacidosis with empagliflozin administration ( $4.3 \%$ with $10 \mathrm{mg}$ and $3.3 \%$ with $25 \mathrm{mg}$ ), although lesser incidents were associated with $2.5 \mathrm{mg}$ dosing $(0.8 \%)$ compared to placebo. Participants that experienced DKA also had one additional precipitation factor, which may include missed or reduced insulin dosing and recent illness/ infection. Symptomatic or severe hypoglycemia was rare in all arms and comparable to placebo. Overall higher incidences of volume depletion and genital infections were also observed in those taking empagliflozin. Additionally, reported adverse drug events were those similarly observed with type 2 diabetes participants receiving SGLT2 inhibitors, including acute renal impairment with observed significant reduction in eGFR (Table 5), and bone fractures [13]. Another phase 2 study among Japanese participants reported similar incidents in rates of adverse drug events where the most reported event was non-severe and asymptomatic hypoglycemia. Moreover, dose dependent increased in ketogenesis markers were observed in all three dosing methods of empagliflozin, however, no events reported DKA [15].

\section{CONCLUSION}

This meta-analysis concluded that empagliflozin has therapeutic benefit as an adjunctive therapy for patients with type 1 diabetes. The findings also concluded that empagliflozin as an adjunctive therapy, holds a strong effect in reducing $\mathrm{Hb} 1 \mathrm{Ac}$ and FBS without increasing the rate of patients reporting adverse drug events. Empagliflozin administration has no effect on increase in urinary glucose excretion with normal insulin daily dosage. Further investigation is, therefore, required on the efficacy and drug-use outcomes of empagliflozin in patients with microvascular complications - especially renal failure.

\section{CONFLICT[S] OF INTEREST}

No conflict[s] of interest to be declared.

\section{FUNDING}

No funding was acquired for this study.

\section{AUTHORS CONTRIBUTION[S]}

All the authors contributed equally to this meta-analysis.

\section{ACKNOWLEDGEMENT}

We would like to thank Ghasna Mohiuddin and Rukhsar Abdul Majeed for their assistance in conducting the meta-anaysis and systematic review.

\section{CONSENT FOR PUBLICATION}

Not applicable.

\section{ORCID iDs}

Syed Wasif Gillani (1)https://orcid.org/0000-0003-4327-2068 Anam Azhar (D)https://orcid.org/0000-0002-0585-1467 Shabaz Mohiuddin Gulam

Fithawit Bahran Gebreigziabher

(1) https://orcid.org/0000-0002-3725-8828

(1) https://orcid.org/ 0000-0002-9263-7767

Hassaan Anwer Rathore (Dhttps://orcid.org/0000-0002-1154-9395

\section{REFERENCES}

1. Zhou, Y, Geng, Z, Wang, X, Huang, Y, Shen, L, Wang, Y. Metaanalysis on the efficacy and safety of SGLT2 inhibitors and incretin based agents combination therapy vs. SGLT2i alone or add-on to metformin in type 2 diabetes. Diabetes Metab Res Rev. 2020;36:e3223.

2. McNeill AM, Davies G, Kruger E, Kowal S, Reason T, Ejzykowicz F, et al. Ertugliflozin compared to other anti-hyperglycemic agents as monotherapy and add-on therapy in type 2 diabetes: A systematic literature review and network meta-analysis. Diabetes Ther. 2019;10(2):473-91.

3. Wang C, Zhou Y, Kong Z, Wang X, Lv W, Geng Z, et al. The renoprotective effects of sodium-glucose cotransporter 2 inhibitors versus placebo in patients with type 2 diabetes with or without prevalent kidney disease: A systematic review and meta-analysis. Diabetes Obes Metab. 2019;21(4):1018-26.

4. Deacon CF, Mannucci E, Ahrén B. Glycaemic efficacy of glucagonlike peptide-1 receptor agonists and dipeptidyl peptidase- 4 inhibitors as add-on therapy to metformin in subjects with type 2 diabetes - a review and meta analysis. Diabetes Obes Metab. 2012;14(8):762-7.

5. Scheen AJ. Reduction in HbA1C with SGLT2 inhibitors vs. DPP-4 inhibitors as add-ons to metformin monotherapy according to baseline HbA1C: A systematic review of randomized controlled trials. Diabetes Metab. 2020;46(3):186-96.

6. Wu D, Li L, Liu C. Efficacy and safety of dipeptidyl peptidase-4 inhibitors and metformin as initial combination therapy and as monotherapy in patients with type 2 diabetes mellitus: a metaanalysis. Diabetes Obes Metab. 2014;16(1):30-7.

7. Liu XY, Zhang N, Chen R, Zhao JG, Yu P. Efficacy and safety of sodium-glucose cotransporter 2 inhibitors in type 2 diabetes: a metaanalysis of randomized controlled trials for 1 to 2 years. J Diabetes Complications. 2015;29(8):1295-303.

8. Castellana M, Cignarelli A, Brescia F, Perrini S, Natalicchio A, Laviola L, et al. Efficacy and safety of GLP-1 receptor agonists as add-on to SGLT2 inhibitors in type 2 diabetes mellitus: A metaanalysis. Sci Rep. 2019;9(1):19351. doi:10.1038/s41598-019-55524-w

9. McHugh KR, De Vore AD, Mentz RJ, Edmonston D, Green JB, Hernandez AF. The emerging role of novel antihyperglycemic agents in the treatment of heart failure and diabetes: a focus on cardiorenal outcomes. Clin Cardiol. 2018;41(9):1259-67.

10. Wu S, Cipriani A, Yang Z, Yang J, Cai T, Xu Y, et al. The cardiovascular effect of incretin-based therapies among type 2 diabetes: a systematic review and network meta-analysis. Expert Opin Drug Saf. 2018;17(3):243-9. 
11. Higgins JP, Altman DG, Gøtzsche PC, Jüni P, Moher D, Oxman AD, et al. The Cochrane Collaboration's tool for assessing risk of bias in randomised trials. BMJ. 2011;343:d5928.

12. DerSimonian R, Laird N. Meta-analysis in clinical trials. Control Clin Trials. 1986;7:177-88.

13. Rosenstock J, Marquard J, Laffel L, Neubacher D, Kaspers S, Cherney $\mathrm{DZ}$, et al. Empagliflozin as adjunctive to insulin therapy in Type 1 diabetes: The EASE Trials. Diabetes Care. 2018;41(12):2560-256.

14. Pieber TR, Famulla S, Eilbracht J, Cescutti J, Soleymanlou N, Johansen OE, et al. Empagliflozin as adjunct to insulin in patients with type 1 diabetes: a 4-week, randomized, placebo-controlled trial (EASE-1). Diabetes Obes Metab. 2015;17:928-35.

15. Shimada A, Hanafusa T, Yasui A, Lee G, Taneda Y, Sarashina S, et al. Empagliflozin as adjunct to insulin in Japanese participants with type 1 diabetes: Results of a 4 -week, double-blind, randomized, placebo-controlled phase 2 trial. Diabetes Obes Metab. 2018;20(9): 2190-9.
16. Perkins B, Cherney D, Partridge H. et al. Sodium-Glucose Cotransporter 2 Inhibition and Glycemic Control in Type 1 Diabetes: Results of an 8-Week Open-Label Proof-of-Concept Trial. Diabetes Care. 2014;37(5):1480-3.

17. Cherney D, Perkins B, Soleymanlou N, Maione M, Lai V, Lee A, et al. Renal hemodynamic effect of sodium-glucose cotransporter 2 inhibition in participants with type 1 diabetes mellitus. Circ. 2014;129(5):587-97.

18. Mathieu C, Eeckhout B. et al. Empagliflozin in type 1 diabetes. Diabetes Metab Syndr Obes. 2019;12:1555-61.

19. Llano A, McKay G, Fisher M. SGLT inhibitors for people with type 1 diabetes. Practical Diabetes. 2019;36:3.

20. Danne T, Garg S, Peters A, Buse JB, Mathieu C, Pettus JH, et al. International consensus on risk management of diabetic ketoacidosis in participants with type 1 diabetes treated with sodium-glucose cotransporter (SGLT) inhibitors. Diabetes Care. 2019;18:2316. 